\title{
Projeto ATO - Ação, Trabalho e Oportunidade: inclusão de pessoas com deficiência no trabalho - relato de experiência
}

\author{
Angela Paula Simonellia , Daniela da Silva Rodrigues ${ }^{\mathrm{b}}$, Paula Márcia Gomes Navas ${ }^{\mathrm{c}}$, \\ Léa Beatriz Teixeira Soares ${ }^{\mathrm{d}}$, Joáo Alberto Camarotto ${ }^{\mathrm{e}}$
}

\begin{abstract}
${ }^{a}$ Doutora em Engenharia de Produção, Universidade Federal de São Carlos - UFSCar, Professora Adjunta do curso de Terapia Ocupacional, Universidade Federal do Paraná - UFPR, Curitiba, PR, Brasil

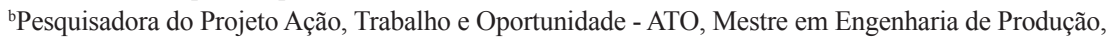
Universidade Federal de São Carlos - UFSCar, Professora Assistente do curso de Terapia Ocupacional, Universidade de Brasília - UNB, Brasília, DF, Brasil

'Terapeuta Ocupacional e Coordenadora de campo do Projeto ATO, Secretaria Municipal de Saúde, Prefeitura de Rio Claro, SP, Brasil

${ }^{\mathrm{d} D o u t o r a}$ em Saúde Coletiva, Universidade Estadual de Campinas - UNICAMP, Professora Associada do Curso de Terapia Ocupacional, Universidade Federal de São Carlos - UFSCar, São Carlos, SP, Brasil

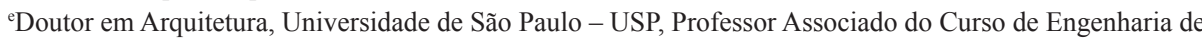
Produção, Universidade Federal de São Carlos - UFSCar, São Carlos, SP, Brasil
\end{abstract}

\begin{abstract}
Resumo: Este artigo relata a experiência do Projeto ATO - Ação, Trabalho e Oportunidade: inclusão de pessoas com deficiência no trabalho em andamento no município de São Carlos desde 2008 a partir da operacionalização de um modelo de inclusão baseado na atividade. Trata-se de uma pesquisa interinstitucional desenvolvida academicamente por meio de uma atividade de extensão ${ }^{1}$. As várias etapas desenvolvidas pela equipe interdisciplinar, os métodos empregados e os fundamentos teóricos que norteiam a consecução dos objetivos pretendidos são descritos. Os resultados quantitativos e qualitativos obtidos até o momento são analisados quanto aos elementos estratégicos facilitadores, bem como das relações de interesse que atuam como impedimentos para a participação das pessoas com deficiência no projeto e para a inclusão destas no trabalho. Verificou-se a necessidade de preparo da sociedade para a superação de barreiras atitudinais e arquitetônicas no ambiente de trabalho, além da difusão da cultura de inclusão e respeito às diferenças nas estruturas organizacionais, políticas e processos das empresas. Algumas propostas que poderiam contribuir para a eficiência de uma política pública de inclusão de pessoas com deficiência no trabalho concluem o presente estudo.
\end{abstract}

Palavras-chave: Inclusão, Pessoas com Deficiência, Trabalho.

\section{Project "ATO - Açáo, Trabalho e Oportunidade" (action, work and opportunity): insertion of disabled people in the labor market - an experience report}

\begin{abstract}
This article reports the experience of the Project "ATO - Ação, Trabalho e Oportunidade" (Action, Work and Opportunity): insertion of disabled people in the labor market in the municipality of São Carlos, state of Sao Paulo, which has been in progress since 2008 through the application of an insertion model based on the activity. It is an interinstitutional research academically developed through an extension activity. It describes the several stages developed by the interdisciplinary team, the methods applied, and the theoretical fundamentals that guide the achievement of the aimed targets. The quantitative and qualitative results found so far are analyzed with respect to the facilitating strategic elements as well as to the relations of interest that act as impediments to the participation of the mentally disabled in the project and for their insertion in the labor market. It was possible
\end{abstract}

Autor para correspondência: Angela Paula Simonelli, Departamento de Terapia Ocupacional, Universidade Federal do Paraná, Av. Lothário Meissner, 632, Jardim Botânico, CEP 80210-170, Curitiba, PR, Brasil, e-mail: angelasimonelli@ufpr.br 
to observe that society needs to be prepared to overcome architectural and attitudinal barriers in the workplace, besides disseminating the concepts of inclusion culture and respect for differences in the organizational structures, policies and processes of companies. Some proposals that could contribute to the efficiency of a public policy of insertion of disabled people in the labor market close the present study.

Keywords: Insertion, Disabled People, Work.

\section{Introdução}

Desde a elaboração da Constituição de 1988 os direitos dos cidadãos brasileiros estão legalmente resguardados, porém, as dificuldades enfrentadas por segmentos populacionais, como por exemplo as pessoas com deficiência e a obtenção e permanência em um emprego, são recorrentes (SIMONELLI, 2009).

$\mathrm{Na}$ perspectiva da mesma autora, para reverter este quadro o país investe em uma política afirmativa para garantir a participação na produção e consumo de bens e valores sociais. Desde a regulamentação de sua vigência pelo Decreto ${ }^{\circ} 3.298 / 99$, a Lei de Cotas (Lei no 8.213/91) fixa percentual de vagas em empresas do setor privado que devem ser preenchidas por pessoas com deficiência.

Dados do IBGE sobre a projeção da população divulgados em 2004 mostram que no Brasil existem 26,5 milhóes de pessoas com deficiência e desses, 16,4 milhôes em idade de trabalhar (CLEMENTE, 2005).

Segundo dados da RAIS 2001 e 2002/MTE, as pessoas com deficiência representam 2,05\% (533 mil) dos 26 milhóes de trabalhadores formais do Brasil, o que revela baixa empregabilidade. Estão proporcionalmente mais presentes na indústria que os trabalhadores em geral $(27,33 \%$ e $19,31 \%$, respectivamente) e têm participação proporcional semelhante no setor de serviços.

A estimativa para pessoas com deficiência no município de São Carlos é de 22.400 pessoas; deste total, cerca de $50 \%$ se encontram na faixa da Populaçáo Economicamente Ativa (SALOMÃO; SIMONELLI, 2006).

Apesar da Lei no 8.213/91 garantir a inserção da pessoa com deficiência no mercado de trabalho, no município de São Carlos apenas 48,7\% das vagas de emprego disponíveis para essa população foram preenchidas. Ausência de informaçóes atualizadas sobre as pessoas com deficiência, inadequação dos espaços dos postos de trabalho e falta de qualificação profissional são alguns dos muitos fatores que justificam essa baixa adesão. Para mudar esse cenário, é necessário implementar açôes interdisciplinares que envolvam todos os atores relacionados à temática da deficiência. Nesse contexto, o projeto apresentado neste artigo torna-se fundamental para amenizar a questão da inserção das pessoas com deficiência no mercado de trabalho (SALOMÃO; SIMONELLI, 2006).

Os empregadores questionam a inflexibilidade da lei, seus percentuais de cotas fixos e a dificuldade de encontrar pessoas qualificadas para preencher suas vagas. Por outro lado crescem as ofertas de serviços de preparação profissional nas instituiçóes de/e para pessoas com deficiência (SIMONELLI, 2009).

Os serviços prestados às pessoas com deficiência, historicamente baseados em conceitos biomédicos, são questionados por não considerarem o contexto e as barreiras sociais que dificultam a participação dessas pessoas na vida em sociedade, por exemplo, na escola, nas atividades de lazer, no trabalho, entre outros. Por outro lado, o modelo social da deficiência se baseia no conceito de que a deficiência está na sociedade e não no indivíduo e que lesão não está diretamente relacionada a deficiência. Este modelo está cada vez mais presente nas ações destinadas às pessoas com deficiência, porém, o modelo hegemônico na prática ainda é o modelo biomédico (SIMONELLI, 2009).

Com a finalidade de superar a reconhecida ineficácia do modelo biomédico centrado na avaliação e no tratamento da incapacidade, predominante nos serviços de reabilitação, o Projeto ATO afirma sua vinculaçáo aos pressupostos teóricos do modelo social da incapacidade (OLIVER, 1960).

O objetivo deste artigo é apresentar o modelo operacional do Projeto ATO - Ação, Trabalho e Oportunidade: inclusão de pessoas com deficiência no trabalho, bem como analisar seus resultados quantitativos e qualitativos quanto aos elementos estratégicos facilitadores, das relaçóes de interesse que atuam como impedimentos para a participação das pessoas com deficiência no projeto e para a inclusão destas no trabalho.

\section{O projeto ATO}

O Projeto ATO tem sua origem derivada de uma rede de açôes para inclusão de pessoas com deficiência 
no mercado de trabalho, desenvolvida no município de São Carlos, através da parceria da Universidade Federal de São Carlos, Gerência Regional do Trabalho e Emprego e Prefeitura Municipal (SALOMÃO; SIMONELLI, 2006).

A discussão e estruturação da referida rede iniciou-se em 2005 devido à alta demanda de contratação, por parte das empresas do município, estimuladas pela fiscalização do cumprimento da Lei $n^{\circ} 8.213 / 91$ e a pequena procura de trabalho por parte das pessoas com deficiência.

A experimentação da rede se deu por meio de um projeto piloto de inserção das pessoas com deficiência no trabalho que ocorreu entre agosto de 2006 e agosto de 2008 com: caracterização populacional, estudo da incapacidade e funcionalidade, qualificação profissional, análise das atividades de trabalho e sistema de acompanhamento do emprego. Por meio desse projeto piloto se intentou iniciar as atividades integradas de inclusão da pessoa com deficiência no mercado de trabalho no município. As análises das atividades de trabalho foram realizadas em uma empresa do setor têxtil (SIMONELLI, 2009) e a Fundação Educacional Sáo Carlos realizou a capacitação profissional fundamentada na formação cidadã, isto é, aquela que oferece conhecimentos generalistas capazes de melhorar as condiçóes de inserção ou reinserção da pessoa com deficiência no mercado de trabalho. Os assuntos abordados no curso compreenderam: autocuidado e autoestima, postura de trabalho, comunicação na empresa, entrevista de emprego, comunicação interpessoal e relacionamentos, assertividade, autonomia e enfrentamento de barreiras.

O Projeto ATO é desenvolvido, desde outubro de 2008, por uma equipe interdisciplinar composta por terapeutas ocupacionais, engenheiros de produção e psicóloga. O projeto é mantido pela parceria estabelecida entre a Universidade Federal de São Carlos (UFSCar), pelos departamentos de Terapia Ocupacional (DTO) e Engenharia de Produção (DEP), pela Prefeitura Municipal de São Carlos (PMSC), Instituto Nacional de Seguridade Social (INSS), Fundação Educacional São Carlos (FESC), Gerência Regional do Trabalho e Emprego de São Carlos (GRT - São Carlos) e Ministério do Trabalho e Emprego (MTE). A coordenação acadêmica é realizada por professores da Universidade Federal de São Carlos, e estagiários ${ }^{2}$ e técnicos promovem a sua operacionalização.

O projeto tem financiamento de uma metalúrgica multinacional localizada na cidade de Sáo Carlos, por meio de um Termo de Ajustamento de Conduta (TAC) do Ministério Público do Trabalho. A partir de dezembro de 2010 a Prefeitura Municipal, a partir de termo de compromisso, assumiu integralmente o projeto.

A divulgação do Projeto ATO foi realizada pela Fundação Educacional Sáo Carlos (FESC) e Secretaria Municipal de Trabalho, Emprego e Renda (SMTER), que contou com a ajuda do Serviço Autônomo de Água e Esgoto (SAAE), por meio da entrega de um folder explicativo das atividades do projeto ATO, contendo endereço, telefone e horários de atendimento, anexo às contas de água dos bairros Cidade Aracy I e II e Santa Felícia. Esses bairros tiveram prioridade na entrega por apresentarem grande quantidade de pessoas com deficiência como moradores.

Além da divulgação em conta de água, a equipe executiva se mobilizou para entregar o folder do projeto em diversas unidades de saúde (Centro Municipal de Especialidades - CEME, Unidade de Saúde da Família - USF, Unidade Básica de Saúde - UBS), tanto dos bairros acima referidos quanto de outros e alguns hipermercados da cidade.

A seguir são destacados os aspectos estruturados do projeto ATO, desenvolvidos por meio do modelo de inclusão baseado na atividade.

\section{Teoria e métodos}

O projeto propóe analisar as pessoas com deficiência, suas potencialidades, conhecimentos, as barreiras e os facilitadores da execução de atividades; os locais de trabalho, posturas exigidas pelas tarefas de trabalho, movimentos, requisitos técnicos e conhecimentos necessários, através da análise da atividade das pessoas sem deficiência que trabalham nos postos (SIMONELLI; CAMAROTTO, 2011).

A classificação das pessoas com deficiência e a análise das atividades de trabalho servem de base para o desenvolvimento da inclusão que visa qualificar as pessoas com deficiência para o trabalho, adequar o local de trabalho e ambiente (espaços, artefatos, acessibilidade e relaçóes sociais) e posteriormente realizar, no estágio profissional, o acompanhamento psicossocial e do desenvolvimento técnico com a análise da atividade das pessoas com deficiência nos postos. A Figura 1 apresenta o modelo:

O modelo utiliza-se do referencial teórico da Análise Ergonômica do Trabalho (GUÉRIN et al., 2001), base para analisar e reconhecer as habilidades necessárias para a realização das tarefas.

A ergonomia pode ser entendida como uma disciplina que reúne conhecimentos e técnicas de diversas áreas do conhecimento, como as ciências 


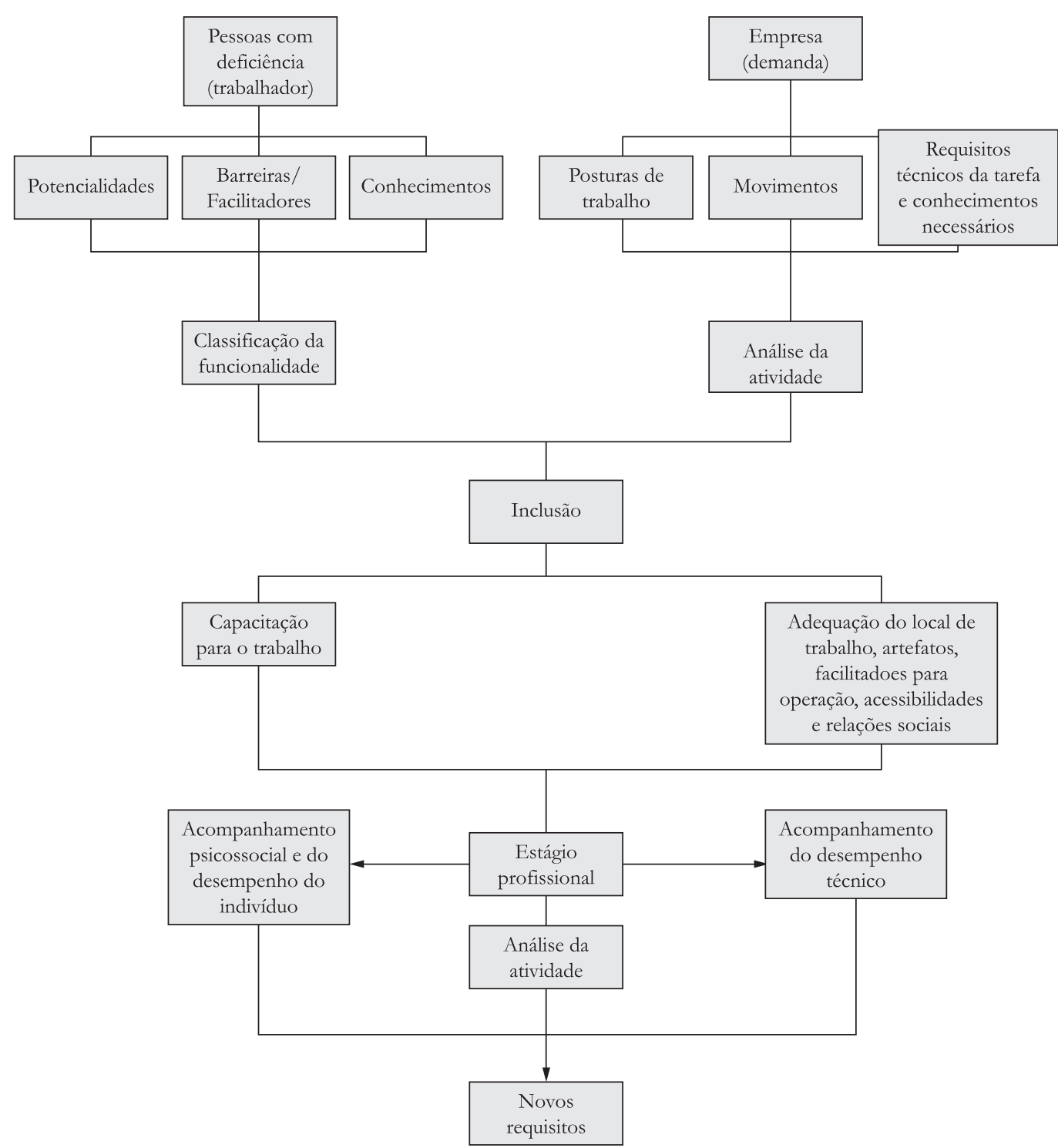

Figura 1. Modelo de inclusão baseado na atividade. Fonte: Simonelli e Camarotto (2011).

do homem (antropometria, fisiologia, psicologia, economia e uma parte da sociologia) e da engenharia (WISNER, 1987).

Segundo Guérin et al. (2001), a Análise Ergonômica do Trabalho tem por base o ponto de vista da atividade de trabalho que pressupóe uma compreensão do trabalho perante uma análise de suas dimensóes física, cognitiva e organizacional.

Os autores acima citados acrescentam ainda que a atividade de trabalho é uma das formas da atividade humana vinculada ao contexto socioeconômico e pessoal, constituída por três aspectos: a tarefa que define o trabalho a ser realizado, antecipando os resultados e determinando as condiçóes para a sua execução, a atividade para a realização das tarefas com a utilização do corpo e da inteligência do homem e os resultados efetivos dessa atividade.
A ergonomia não estabelece diferença quanto ao trabalhador apresentar deficiência ou não, por isso pode-se afirmar que náo existe uma ergonomia especial para pessoas com deficiência, mas ela pode apresentar soluçóes específicas para certos problemas, sejam estes de caráter fisiológico, patológico, transitório ou de diferentes tipos de invalidez (ZURIMENDI, 1994).

Por meio da utilização de um conjunto de métodos e técnicas, neste modelo busca-se indicar as tarefas potenciais para serem realizadas por pessoas com deficiência analisando as necessidades das tarefas e as potencialidades das pessoas com deficiência através da Classificação Internacional de Funcionalidade, Incapacidade e Saúde - CIF (BUCHALLA, 2003), oferecendo parâmetros para as açóes das empresas nas 
políticas de contratação dessa população. Busca-se atender as características das pessoas com deficiência e contemplar suas necessidades específicas.

A CIF é baseada na integração dos modelos biomédico, psicológico e social. A CIF fornece, por essa síntese, uma visão coerente de diferentes perspectivas da saúde: biológica, individual e social. A funcionalidade e a incapacidade de uma pessoa são concebidas como uma interação dinâmica entre os estados de saúde (doenças, perturbaçóes, lesôes etc.) e os fatores contextuais (fatores ambientais e pessoais) (BUCHALLA, 2003). A incapacidade não é um atributo da pessoa, mas sim um conjunto complexo de condiçôes que resulta da interação pessoa-meio.

Para facilitar a compreensão, os procedimentos estão divididos em três etapas: análise das tarefas e atividades de trabalho, classificação de funcionalidade e inclusão.

\subsection{Etapa 1. Estudo das tarefas e atividades de trabalho}

Essa etapa constituiu-se de: análise da tarefa, estudo da atividade e seleçáo dos postos de trabalho indicados às pessoas com deficiência.

A análise da tarefa consiste neste modelo na aplicaçáo de entrevistas com os supervisores dos setores da empresa. O estudo da atividade consiste da descrição e análise das ações dos trabalhadores em atividade, filmagem da atividade de trabalho e análise cinesiológica e aplicação de uma ferramenta para auxiliar no reconhecimento das habilidades necessárias à realização da tarefa (SILVA; EMMEL, 1993). Esse método de análise da atividade é validado com a confrontação dessa representação junto aos trabalhadores e supervisores.

O conhecimento advindo da análise da atividade de trabalho permite compreender como os trabalhadores realizam suas atividades de trabalho, explicar quais os mecanismos que o trabalhador possui para atingir seus objetivos com menor desgaste e avaliar a carga de trabalho envolvida nesse processo. Serve também de subsídio para analisar as habilidades necessárias que o trabalhador deve possuir para realizar efetivamente a atividade executada.

A seleção dos postos de trabalho analisados para a inclusão das pessoas com deficiência indica as habilidades necessárias para a realização da tarefa.

\subsection{Análise da tarefa}

São realizadas entrevistas semiestruturadas com os supervisores das tarefas com o objetivo de obter informaçóes sobre a tarefa e no que se refere à sua descrição. Além disso, busca-se informações sobre:

a) O sistema de rodízio, isto é, procura-se entender se o trabalhador daquela tarefa necessita trabalhar também em outras tarefas;

b) A possibilidade de realização individual, ou seja, tarefas nas quais o trabalhador se dedica do início ao final de seu turno num mesmo local executando o mesmo conjunto de tarefas;

c) Considerações sobre a influência dos fatores tempo e velocidade, isto é, procura-se entender se é prescrito ao trabalhador um tempo de realizaçáo para a tarefa, ou para cada etapa da tarefa, e se é imposto algum ritmo de trabalho para o trabalhador, a fim de cumprir as metas de produção;

d) Esclarecimentos sobre a interligação entre as tarefas, ou seja, se há uma interdependência entre a tarefa realizada por um trabalhador e a tarefa realizada por outro trabalhador;

e) Informaçôes e opinióes sobre a possibilidade da empresa de receber pessoas com deficiência para serem trabalhadores naquelas tarefas; e

f) Indaga-se sobre a posição do supervisor frente à inclusão.

As entrevistas gravadas são transcritas integralmente e depois submetidas a uma leitura criteriosa, a fim de analisar o conteúdo a partir da classificação dos trechos por categorias pertinentes ao objeto de estudo.

\subsection{Estudo da atividade}

A observação e registro das situações de trabalho são baseados no Ergonomics Workplace Analisys - EWA), desenvolvido pelo Instituto Finlandês de Saúde Ocupacional e adaptado pela UFSCar. O EWA agrega diferentes conhecimentos em sua base teórica: fisiologia do trabalho, biomecânica ocupacional, aspectos psicológicos, higiene ocupacional e o modelo sociotécnico da organização do trabalho (AHONEN; LAUNIS; KUORINKA, 1989).

Todos os registros têm por base o desempenho de trabalhadores sem deficiências e são feitos a partir da observação e da análise das atividades de trabalho.

Realiza-se a descrição das açôes dos trabalhadores para entender as atividades de trabalho. As expressóes dos trabalhadores são gravadas, transcritas integralmente, submetidas à leitura prévia para correçóes e posteriormente confrontadas com esses 
trabalhadores para validação. Deste conteúdo são retirados trechos por categorias pertinentes ao objeto do estudo.

São realizadas filmagens das atividades de trabalho para análise cinesiológica e biomecânica das posturas e movimentos necessários à realização da atividade.

As filmagens são realizadas durante a atividade de trabalho, procura-se realizar tomadas no plano anterior, posterior, lateral e superior, a fim de obter imagens que ao serem editadas em programa específico de computador possam favorecer o tratamento das imagens e assim quantificadas as amplitudes articulares dos movimentos realizados durante a atividade de trabalho. Esse procedimento, assim como os demais, é realizado com autorização prévia da empresa.

Durante a observação da atividade de trabalho, além das anotaçôes em fichas de registros de campo o modelo propóe a aplicação de um instrumento desenvolvido por Silva e Emmel (1993). Esse instrumento foi adaptado por Emmel et al. (2002) com a finalidade de reconhecer as habilidades necessárias para a realizaçáo de atividades em postos de trabalho.

\subsection{Seleção dos postos de trabalho}

Os resultados anteriores possibilitam conhecer as tarefas e as atividades nos postos analisados, os movimentos, as habilidades, os conhecimentos e requisitos técnicos necessários para a realização destas. Essa seleção gera relatório com informações entregue à empresa para orientar a colocaçáo das pessoas com deficiência a fim de contribuir para a maior permanência delas nos postos selecionados.

\subsection{Etapa 2. Classificação da funcionalidade das pessoas com deficiência}

Para a classificação da capacidade funcional das pessoas com deficiência selecionou-se o instrumento desenvolvido pela Organização Mundial da Saúde - OMS, a Classificação Internacional da Funcionalidade, Incapacidade e Saúde - CIF, pois este modelo substitui o enfoque negativo da deficiência e da incapacidade por uma perspectiva positiva, considerando as atividades que um indivíduo que apresenta alteraçôes de função e/ou da estrutura do corpo pode desempenhar, assim como sua participaçáo social. A funcionalidade e a incapacidade dos indivíduos são determinadas pelo contexto ambiental onde as pessoas vivem.
As classificaçóes consistem em análise de relato clínico e histórico ocupacional, além de avaliações clínicas da estrutura do corpo, seguindo a proposta da classificação da OMS.

\subsection{Etapa 3. Inclusão}

A inclusão visa à preparação social e técnica das pessoas com deficiência para o trabalho, adequação do local de trabalho e ambiente (espaços, artefatos, acessibilidade e relaçóes sociais) e o acompanhamento psicossocial e do desenvolvimento técnico das pessoas com deficiência em estágio profissional.

Os cursos de capacitação estruturaram-se com carga horária de 30 horas, foram baseados na metodologia da Instituição Sorri-Campinas e trabalham os seguintes temas: autocuidado e autoestima, comunicação na empresa, entrevista de emprego, dinâmicas de grupo, comunicação interpessoal, valorizaçáo de relacionamentos, rede de contatos, pensamento positivo, autonomia, enfrentamento de barreiras, acessibilidade, direitos e deveres, postura profissional, visão de processo na organizaçáo, autonomia e cultura de inclusão.

Simultaneamente um curso sobre educação para a inclusão é realizado com os trabalhadores da empresa, a fim de apresentar as características das pessoas com deficiência, discutir suas habilidades e limitaçóes e as barreiras impostas pela sociedade à inclusão.

Ao término desses cursos preparatórios para a inclusão, que fornecem informações tanto para as pessoas com deficiência quanto para a sociedade (empresa), para garantir adaptaçóes e relacionamentos inclusivos, as pessoas com deficiência iniciam os estágios na empresa, com carga horária de quatro horas diárias durante três meses, nas atividades previamente analisadas e com acompanhamento pela equipe do projeto.

\section{Resultados}

No período de dezembro de 2008 a agosto de 2010, foram analisados 74 postos de trabalho na empresa metalúrgica parceira e financiadora deste projeto, segundo a metodologia proposta. A Figura 2 apresenta os postos distribuídos por setores da empresa.

Os postos analisados estavam distribuídos em 15 setores da empresa, sendo o setor da Compela e Montagem, ambos setores da produçáo, os que apresentaram maior número de atividades possíveis de indicação, seguidos da Estamparia e 
do Bobinado. Os setores da Compela e Montagem caracterizam-se por atividades desenvolvidas em bancada, com manipulação de peças pequenas e leves, em posição sentada e poucos deslocamentos. Os setores apresentam pouco ruído em comparação com os demais.

Simultaneamente à análise das atividades de trabalho, foram cadastradas 226 pessoas que procuraram pelo projeto ATO. Destas 226 pessoas, 131 pessoas foram avaliadas. A Figura 3 apresenta os encaminhamentos das pessoas ao projeto.

As 131 pessoas avaliadas foram convidadas a realizar o curso de capacitaçáo oferecido pelo projeto. A Figura 4 apresenta a distribuição das pessoas por tipo de deficiência. As pessoas que não foram avaliadas e não foram convidadas para o curso de capacitação, total de 95 pessoas, não se enquadravam nos critérios de elegibilidade, segundo o Decreto $n^{\circ} 3.298 / 99$ que as classificasse como pessoas com deficiência. O Quadro 1 apresenta os dados sociodemográficos da população, que foi avaliada.

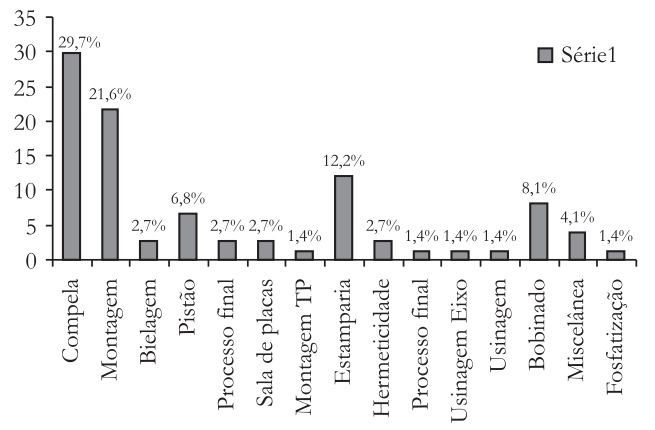

Figura 2. Postos de trabalho distribuídos por setores da empresa.
A partir da análise do Quadro 1, é possível verificar que das pessoas que foram convidadas a frequentar $\mathrm{o}$ curso de capacitação profissional, há predominância de homens, com faixa etária de 26 a 35 anos; já em relação à escolaridade, a predominância é de pessoas que concluíram o ensino médio e possuem experiência profissional tanto em mercado formal de trabalho quanto em mercado informal.

As pessoas que foram avaliadas pelo Projeto ATO, segundo Figura 3, em sua maioria foi encaminhada pelo INSS e pela prefeitura municipal por meio da Casa do Trabalhador e houve procura considerável derivada de anúncio em conta de água do município.

Segundo Figura 4, a maior parte das pessoas avaliadas e convidadas para frequentar o curso de capacitação apresenta deficiência física e deficiência mental leve, de acordo com Decreto no 3.298/99 e destaca-se que grande parcela foi composta por reabilitados do INSS, geralmente pessoas que possuem alguma doença ocupacional.

O curso de capacitação foi realizado em 7 turmas, cujo conteúdo programático foi dividido em 30 horas. Concluíram o curso 87 pessoas com deficiência. O Quadro 2 apresenta as características sociodemográficas das pessoas que concluíram o curso de capacitação, bem como a Figura 5 mostra a distribuiçáo das pessoas que concluíram o curso por tipo de deficiência.

A partir da análise do Quadro 2, é possível verificar que das pessoas que concluíram o curso de capacitação profissional, a faixa etária que predomina é a de 26 a 35 anos; já em relação à escolaridade, a predominância é de pessoas, que concluíram o ensino médio. Quanto ao sexo, verifica-se que os

Quadro 1. Dados sociodemográficos da população avaliada e convidada para a turma de capacitação profissional pelo Projeto ATO.

\begin{tabular}{|c|c|c|c|}
\hline \multicolumn{4}{|c|}{ Tabela com dados sociodemográficos dos que foram convidados e não frequentaram a capacitação } \\
\hline Idade (anos) & Número pessoas & Escolaridade & Número pessoas \\
\hline $15-25$ & 32 & Ensino fundamental completo & 18 \\
\hline $26-35$ & 47 & Ensino fundamental incompleto & 35 \\
\hline $36-45$ & 30 & Ensino médio completo & 55 \\
\hline $46-55$ & 16 & Ensino médio incompleto & 12 \\
\hline $56-60$ & 5 & Ensino superior completo & 2 \\
\hline \multirow[t]{2}{*}{ Acima de 60 anos } & 1 & Ensino superior incompleto & 4 \\
\hline & \multirow[b]{2}{*}{ Número pessoas } & Outras escolas (APAE, ACORDE) & 5 \\
\hline Sexo & & Experiência de trabalho & Número pessoas \\
\hline Feminino & 58 & Mercado formal & 36 \\
\hline \multirow[t]{3}{*}{ Masculino } & 73 & Mercado informal & 15 \\
\hline & & Mercado formal e informal & 65 \\
\hline & & Nunca trabalhou & 15 \\
\hline
\end{tabular}




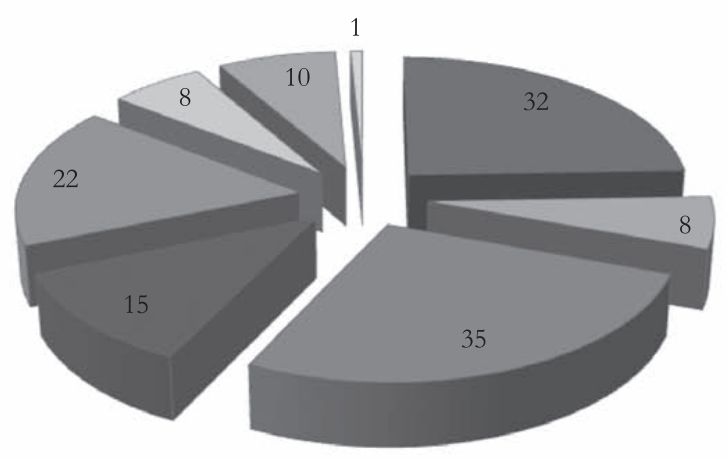

- Prefeitura $=32$

$\square$ Unidade Saúde Escola (USE) - UFSCar $=8$

$\square$ INSS $=35$

- Demanda espontânea, outra universidade, rádio ou usuário do projefo $=15$

$\square$ Propaganda em conta de água $=22$

$\square$ Funcionários da Tecumseh $=8$

$\square$ Funcionários da equipe ATO $=10$

$\square$ Associação de capacitação, orientação e desenvolvimento ao excepcional - ACORDE $=1$

Figura 3. Distribuição dos encaminhamentos e demandas espontâneas.

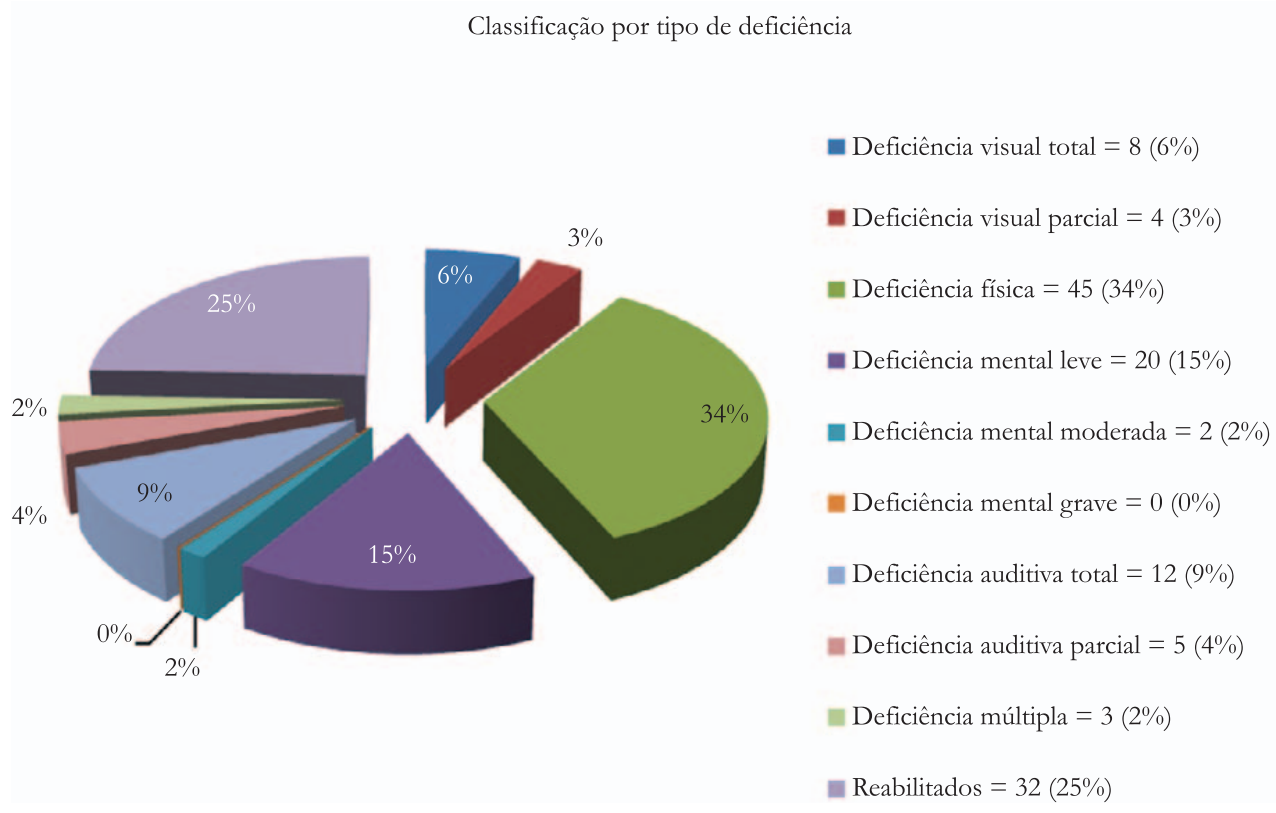

Figura 4. Distribuição das pessoas que foram avaliadas e convidadas para as turmas de capacitação pelo projeto por tipo de deficiência.

homens são os que mais frequentaram e concluíram o curso de capacitação.

Ainda sobre os dados sociodemográficos, verifica-se que a maior parte das pessoas com deficiência possui experiência profissional tanto em mercado formal de trabalho quanto em mercado informal.

Segundo a Figura 5, dentre as pessoas que concluíram o curso de capacitação oferecido pelo projeto a grande maioria apresenta deficiência física e deficiência mental leve, segundo Decreto n 3.298/99.

Em relação aos encaminhamentos para o mercado de trabalho formal, das 87 pessoas concluintes do curso de capacitação profissional 82 foram encaminhadas para o mercado de trabalho formal.
As 5 pessoas restantes foram indicadas a compor o programa de economia solidária da Secretaria de Trabalho, Emprego e Renda da Prefeitura do Município de São Carlos.

As 82 pessoas com deficiência indicadas para postos de trabalho no mercado formal foram indicadas para iniciar estágio profissional na metalúrgica financiadora do projeto. Depois de concluído o estágio profissional, 28 pessoas foram contratadas pela metalúrgica, ou seja, $34 \%$ das pessoas indicadas para estágio profissional.

Durante o período de execução do projeto, especificamente em 2009, foi realizado treinamento com supervisores, funcionários da Produção e de 

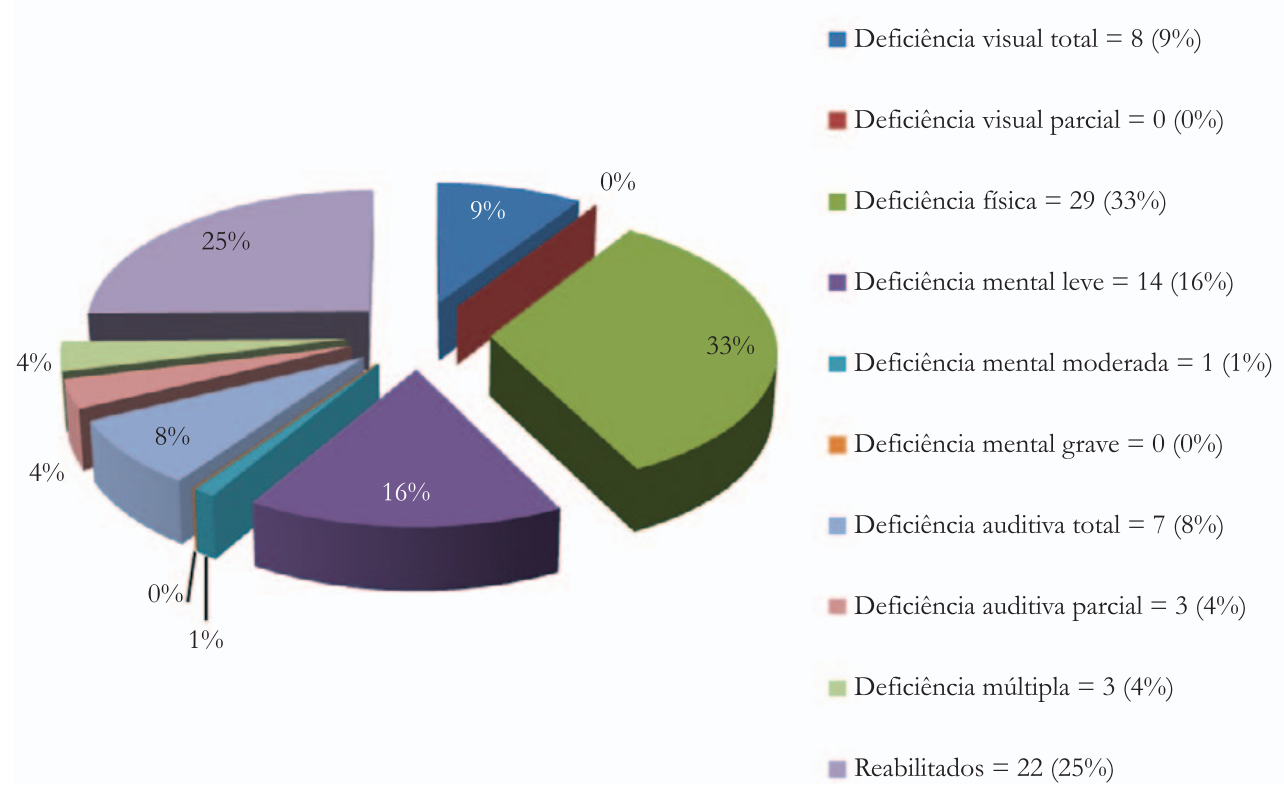

Reabilitados $=22(25 \%)$

Figura 5. Distribuição das pessoas que concluíram o curso oferecido pelo projeto por tipo de deficiência.

Quadro 2. Dados sociodemográficos das pessoas avaliadas e que concluíram o curso de capacitação.

\begin{tabular}{|c|c|l|c|}
\hline \multicolumn{4}{|c|}{ Tabela com dados sociodemográficos dos que concluíram a capacitação profissional } \\
\hline Idade (anos) & Número pessoas & \multicolumn{1}{c|}{ Escolaridade } & Número pessoas \\
\hline $15-25$ & 20 & Ensino fundamental completo & 8 \\
\hline $26-35$ & 31 & Ensino fundamental incompleto & 21 \\
\hline $36-45$ & 20 & Ensino médio completo & 42 \\
\hline $46-55$ & 10 & Ensino médio incompleto & 10 \\
\hline $56-60$ & 5 & Ensino superior completo & 1 \\
\hline Acima de 60 anos & 1 & Ensino superior incompleto & 3 \\
\hline \multicolumn{2}{|c|}{} & Outras escolas (APAE, ACORDE) & 2 \\
\hline Sexo & Número pessoas & Experiência de trabalho & Número pessoas \\
\hline Feminino & 41 & Mercado formal & 29 \\
\hline Masculino & 46 & Mercado informal & 9 \\
\hline \multicolumn{2}{|c|}{} & Mercado formal e informal & 43 \\
\cline { 2 - 4 } & & Nunca trabalhou & 6 \\
\hline
\end{tabular}

Recursos Humanos da empresa, a fim de prepará-los para receber as pessoas com deficiência para o estágio. O treinamento teve duração de 4 horas, foram realizadas palestra e dinâmica grupal com os 75 funcionários que participaram.

Também durante este período foi realizada visita técnica na empresa metalúrgica em São Carlos para verificação das condiçốes de acessibilidade para pessoas com deficiência.

Verificou-se que as catracas das entradas principais e de um setor de peças eletrônicas não possuem passagem adequada para uma pessoa que utilize cadeira de rodas (cadeirante). Todavia, o porteiro pode acionar a catraca com o cartão magnético do funcionário e este ter seu acesso lateralmente à catraca. No entanto, sugeriu-se ampliar a passagem respeitando-se as normas regulamentadoras para usuário de cadeira de rodas. $\mathrm{O}$ acesso do cadeirante à unidade de produçáo se faz possível através da rampa da ambulância.

Para a utilizaçáo do restaurante existe uma passagem de $82 \mathrm{~cm}$ de largura, ao lado da catraca no corredor de saída dos funcionários e há um acesso (saída de emergência), lateralmente à portaria principal, pelo estacionamento da gerência, que pode ser usado pelo cadeirante. O ideal seria a adequação 
do corredor de entrada do restaurante para o acesso dos cadeirantes.

Existem vestiários no piso térreo para os trabalhadores e banheiros comuns. Não existe nenhum banheiro adaptado na empresa. A distância entre os armários permite deambulação independente. O armário a ser destinado deve ter altura compatível com um cadeirante.

Caixas de banco estão disponíveis para pessoas com deficiência física, auditiva e visual próximos ao refeitório.

Não existe nenhum indicador tátil para pessoa com deficiência visual, seja no percurso interno ou externo à empresa. Tampouco existem indicadores sonoros ou escritos em braile ou em relevo. Verificou-se a necessidade de instalaçáo do piso tátil de alerta e indicação no início e final das escadas, delimitação do percurso interno com indicador tátil para a segurança em toda planta, principalmente nos setores de produção. Indicação em braile nas bases dos corrimãos das escadas e indicaçôes sonoras, bem como promover manutenção das faixas antiderrapantes das escadas.

Já no período final do projeto, 2010, foram oferecidos pelo Projeto ATO cursos de capacitaçáo sobre a metodologia utilizada pelo projeto à equipe interna da empresa, a fim de que esta pudesse dar continuidade às análises e avaliaçôes necessárias à inclusáo responsável de pessoas com deficiência na empresa.

\section{Discussão}

Os resultados apresentados ao serem analisados quanto aos elementos estratégicos facilitadores, bem como às relaçóes de interesse que atuam como impedimentos para a participação das pessoas com deficiência no projeto e para a inclusão destas no trabalho, destacaram alguns fatores a serem discutidos: acessibilidade no local de trabalho, prevalência de pessoas reabilitadas pelo programa de reabilitação profissional do INSS, índice de contrataçôes, financiamento do projeto de caráter privado e por meio de Termo de Ajustamento de Conduta do MTE.

De acordo com visita técnica realizada na planta da empresa os espaços foram diagnosticados como inapropriados para o livre acesso de pessoas que utilizam cadeiras de rodas, seja para a entrada na fábrica, setor de produção, restaurante e vestiário. $\mathrm{O}$ mesmo foi verificado para o acesso dos deficientes visuais. A questão da acessibilidade dificultou o desempenho de algumas pessoas com deficiência nos estágios desenvolvidos pelo projeto nesta empresa, bem como sua permanência nela. Trata-se de um ambiente não apropriado para garantir condições de trabalho e segurança a esta população, apesar da Lei $\mathrm{n}^{\circ} 10.098$ em vigor desde 19 de dezembro de $2000 \mathrm{e}$ que em seu capítulo $V$ dispóe da acessibilidade nos edifícios de uso privado (BRASIL, 2000).

Verificou-se a prevalência de pessoas encaminhadas pelo INSS para a realização dos cursos de capacitação no projeto, já que pessoas que recebem certificado de reabilitação profissional por essa instituição são consideradas nas cotas das empresas. Essas pessoas são encaminhadas após cumprirem o programa de reabilitação profissional desenvolvido por tal instituição. Esse resultado corrobora com Simonelli (2009) e Oliver (1960) ao referirem-se aos serviços prestados às pessoas com deficiência, historicamente baseados em conceitos biomédicos, reconhecidamente ineficazes, centrados na avaliaçâo e no tratamento da incapacidade ainda hegemônico nos serviços de reabilitação, assim como no Sistema Previdenciário Brasileiro, pois continua-se não considerando o contexto e as barreiras sociais que dificultam a participação dessas pessoas na vida em sociedade. Caso contrário, o programa de reabilitação profissional do INSS finalizaria o processo de reabilitação na negociação com a empresa de origem para possível alocação do segurado em um novo posto de trabalho adequado e o Projeto ATO se ocuparia apenas da capacitação profissional e inserçáo no trabalho das pessoas com deficiência.

Apesar de todo o processo desenvolvido que considerou o contexto, os fatores ambientais e pessoais que poderiam ser facilitadores e/ou barreiras ao desenvolvimento de atividades de trabalho pelas pessoas com deficiência nesta empresa, questiona-se a contratação pela empresa de apenas $34 \%$ das pessoas qualificadas e indicadas para atividades de trabalho compatíveis previamente analisadas. Esse resultado novamente remete a discussão à questáo apresentada por Simonelli (2009) em que os empregadores questionam a inflexibilidade da lei, seus percentuais de cotas e a dificuldade de encontrar pessoas qualificadas para preencher suas vagas. Porém, nessa experiência, as pessoas foram qualificadas nas atividades específicas para as quais iriam trabalhar nessa empresa e não foi suficiente. Vale ressaltar que a maioria das pessoas que participaram do programa caracterizava-se em idade produtiva, entre 26 e 35 anos, jovens do sexo masculino, com ensino médio e experiência profissional no mercado formal e/ou informal.

Dessa forma, ações de fiscalização do Ministério do Trabalho e Emprego (MTE) incluíram no mercado de trabalho 143.631 pessoas com deficiência desde 2005. Balanço divulgado pela Secretaria de 
Inspeção do Trabalho do MTE mostra ainda que o número de inserçóes tem aumentado ano a ano: em 2005, foram 12.786 pessoas, saltando para 28.752 ao final de 2010 . O número representa um aumento de 124,8\% em 5 anos (BRASIL, 2011). Torna-se importante destacar que este projeto foi financiado por um Termo de Ajustamento de Conduta determinado pelo MTE, mostrando a efetividade das açóes de fiscalização desse ministério no município de São Carlos.

\section{Considerações finais}

Nos três primeiros meses de 2011, 7.508 pessoas com algum tipo de deficiência foram inseridas no mercado de trabalho formal, um crescimento de $40,7 \%$ em relação ao primeiro trimestre de 2010, quando foram incluídos 5.338 trabalhadores (BRASIL, 2011). Esses dados constatam que a contratação das pessoas com deficiência já é uma realidade das empresas brasileiras.

Porém, verifica-se que apenas ações pautadas na eficiência das fiscalizaçôes às empresas privadas para o cumprimento da lei não garantem linearidade na participação das pessoas com deficiência no trabalho. É necessário o preparo da sociedade para a superação de barreiras atitudinais e arquitetônicas no ambiente de trabalho, além da difusão da cultura de inclusão e respeito às diferenças nas estruturas organizacionais, políticas e processos das empresas.

\section{Referências}

AHONEN, M.; LAUNIS, M.; KUORINKA, T. (Eds.). Ergonomics Workplace Analysis. Helsink: Finnish Institute of Occupational Health, Ergonomics Section, 1989.

BRASIL. Ministério das Comunicaçōes. Lei no 10.098 , de 19 de dezembro de 2000. Estabelece normas gerais e critérios básicos para a promoção da acessibilidade das pessoas portadoras de deficiência ou com mobilidade reduzida, e dá outras providências. Diário Oficial da República Federativa do Brasil, Brasília, DF, 20 dez. 2000. Seção 1. Disponível em: <http://www.planalto.gov.br/ ccivil_03/Leis/L10098.htm>. Acesso em: 21 maio 2011.

BRASIL. Pessoas com deficiência conquistam mais emprego. Em Questão, Brasília, p. 01, edição 1277, 2011.
BUCHALLA, C. M. (Org.). Classificação Internacional de Funcionalidade, Incapacidade e Saúde - CIF. Sáo Paulo: Editora da Universidade de São Paulo, 2003.

CLEMENTE, C. A. Trabalhando com a diferença: responsabilidade social e inclusão de portadores de deficiência. Osasco: Espaço da Cidadania, 2005.

EMMEL, M. L. G. et al. Identificação das áreas e postos de trabalho com potencial para receber pessoas portadores de necessidades especiais. In: CONGRESSO LATINO-AMERICANO DE ERGONOMIA, 7.; SEMINÁRIO BRASILEIRO DE ACESSIBILIDADE INTEGRAL, 1.; CONGRESSO BRASILEIRO DE ERGONOMIA, 10., 2002, Recife. Anais... Recife: ABERGO, 2002.

GUÉRIN, F. et al. Compreender o trabalho para transformá-lo: A prática da Ergonomia. 2. ed. São Paulo: Edgard Blücher, 2001.

OLIVER, M. The politics of disablement. London: MacMillan, 1960.

SALOMÃO, S.; SIMONELLI, A. P. Desenvolvimento de rede de açóes para a inclusão de pessoas com deficiência no mercado de trabalho no município de Sáo Carlos. In: ENCONTRO NACIONAL DE ENGENHARIA E DESENVOLVIMENTO SOCIAL, 3., 2006, Rio de Janeiro. Anais... Rio de Janeiro: ABEPRO, 2006.

SILVA, C. C. B.; EMMEL, M. L. G. Jogos e brincadeiras: roteiro de análise de atividades para o terapeuta ocupacional. Cadernos de Terapia Ocupacional da UFSCar, UFSCar, São Carlos, v. 4, n. 1-2, p. 46-62, 1993.

SIMONELLI, A. P. Contribuiçōes da análise da atividade e do modelo social para a inclusão no trabalho de pessoas com deficiência. 2009. 221 f. Tese (Doutorado em Engenharia de Produçáo)-Universidade Federal de São Carlos, São Carlos, 2009.

SIMONELLI, A. P.; CAMAROTTO, J. A. Análise de atividades para a inclusão de pessoas com deficiência no trabalho: uma proposta de modelo. Gestão \& Produção, São Carlos, v. 18, n. 1, p. 13-26, 2011. http://dx.doi. org/10.1590/S0104-530X2011000100002

WISNER, A. Por dentro do trabalho: ergonomia, método \& técnica. São Paulo: Oboré, 1987.

ZURIMENDI, M. M. Conceptos de ergonomia: critérios para La adaptacíon persona - puesto. In: FUNDACÍON MAPFRE MEDICINA. Metodologias y Estratégias para la Integracion Laboral. Madrid: Mapfre, 1994. p. 92-99. 


\section{Contribuição dos Autores}

Angela Paula Simonelli, Daniela da Silva Rodrigues e João Alberto Camarotto - realizaram a pesquisa, redigiram e revisaram o manuscrito. Léa Beatriz Teixeira Soares - revisão de texto. Paula Márcia Gomes Navas - coleta de dados de campo.

\section{Notas}

${ }^{1}$ Este projeto é realizado por meio de equipe técnica contratada e financiada por uma empresa metalúrgica. A equipe é supervisionada por professores e pesquisadora da Universidade Federal de Sáo Carlos que utilizam o espaço para o desenvolvimento de pesquisas e para campo de estágio por meio de convênio. Neste convênio as atividades da universidade se desenvolvem como Atividade de Extensão - Universidade Federal de São Carlos. Empregabilidade de pessoas com deficiência no município de São Carlos. Processo número: 23.112.004801/2010-57.

${ }^{2}$ Os acadêmicos dos cursos de Terapia Ocupacional e Engenharia de Produção participam de todas as etapas do projeto. 